\title{
WEBSITES DOS PODERES EXECUTIVOS ESTADUAIS E AS CONTRATAÇÕES EMERGENCIAIS EM MEIO À PANDEMIA DA COVID-19: HÁ TECNOLOGIA, MAS FALTA TRANSPARÊNCIA
}

\author{
STATE EXECUTIVE POWERS' WEBSITES AND EMERGENCY HIRING AMID THE COVID-19 \\ PANDEMIC: THERE IS TECHNOLOGY, BUT LACK TRANSPARENCY
}

\author{
FABIANO MAURY RAUPP \\ Doutor em Administração pela Universidade Federal da Bahia (UFBA) \\ Professor Associado da Escola Superior de Administração e Gerência (ESAG) \\ Universidade do Estado de Santa Catarina (UDESC) \\ Orcid: 0000-0001-9533-2574 / E-mail: fabianoraupp@hotmail.com \\ Av. Madre Benvenuta, 2037, Itacorubí, Florianópolis - SC, Brasil - CEP: 88035-001 \\ JOSÉ ANTONIO GOMES DE PINHO \\ Doutorado em Regional Planning pela University of London \\ Professor Titular Aposentado Escola de Administração - Universidade Federal da Bahia (UFBA) \\ Pesquisador EAESP - Fundação Getúlio Vargas \\ Orcid: 0000-0002-4122-3652 / E-mail: jagp@ufba.br
}

Submissão: 01/06/2020. Revisão: 02/11/2020. Aceite: 05/11/2020. Publicação: 18/12/2020. DOI: http://dx.doi.org/10.22277/rgo.v14i1.5549

\section{RESUMO}

O objetivo do artigo é analisar o atendimento dos poderes executivos estaduais aos requisitos de transparência nas contratações emergenciais para enfrentamento da COVID-19. Fez-se uma pesquisa descritiva, por meio de um estudo documental, predominando a abordagem qualitativa. Os dados foram obtidos a partir de relatórios da Transparência Internacional Brasil, e analisados à luz do formalismo. Somadas as quantidades de estados nos níveis regular e ruim, é possível perceber que a maioria dos poderes executivos apresenta níveis insuficientes de transparência (51,86\%). Estes resultados seriam explicados, principalmente, pelo desempenho nas dimensões Informações disponíveis (categoria informações desejáveis) e Formato das informações. A tecnologia existe, e em abundância, mas falta transparência.

Palavras-chave: Transparência. Contratações emergenciais. COVID-19. Estados.

\begin{abstract}
The objective of the article is to analyze the compliance of state executive powers with the transparency requirements in emergency contracts to face COVID-19. Descriptive research was carried out through a documentary study, with a qualitative approach. The data were obtained from reports of Transparency International Brazil and analyzed in the light of formalism. Adding up the number of states at regular and bad levels, it is possible to notice that most executive powers have insufficient levels of transparency (51.86\%). These results would be explained, mainly, by the performance in the dimensions Information available (category desirable information) and Format of the information. The technology exists, and in abundance, but it lacks transparency.
\end{abstract}

Keywords: Transparency. Emergency contracts. COVID-19. States. 
Websites dos poderes executivos estaduais e as contratações emergenciais em meio à pandemia da COVID-19: há tecnologia, mas falta transparência

\section{INTRODUÇÃO}

Em meio à pandemia da COVID-19, as contratações emergenciais pelos poderes executivos - federal, estadual e municipal - tornaram-se frequentes, uma vez que o Brasil e o mundo encontram-se em um período definitivamente excepcional que demanda a adoção de medidas emergenciais para a contenção do novo coronavírus. A flexibilização das regras para a realização de contratações públicas tem sido entendida como uma medida necessária para possibilitar que governos respondam de maneira célere aos desafios que o cenário impõe, notadamente na área da saúde (TRANSPARÊNCIA INTERNACIONAL BRASIL, 2020c).

No contexto brasileiro, a Lei n. 13.979, de 06 de fevereiro de 2020, regulamentou as medidas da emergência de saúde pública para enfrentamento da COVID-19. Considerando o tema do estudo, a transparência na contratações emergenciais em tempos de COVID-19, destaca-se 0 § 2 o do art. 4ㅇ do referido documento legal, que define para todas as contratações ou aquisições sua imediata disponibilização em sítio oficial, contendo, no que couber, além das informações previstas no $\S 30$ do art. $8^{\circ}$ da Lei n. 12.527 , de 18 de novembro de 2011․․ (BRASIL, 2011; BRASIL, 2020).

Em paralelo às garantias de atendimento das normas legais, "as iniciativas de transparência na administração pública constituem uma política de gestão responsável que favorece o exercício da cidadania pela população" (PLATT NETO et al., 2007, p. 76-77). A transparência não deve ser confundida com publicidade, isso porque "a informação pode ser pública, mas não ser relevante, confiável, tempestiva e compreensível" (PLATT NETO et al., 2007, p. 76-77). A diferença é a exigência da publicidade é atendida com a publicação dos atos poder público no veículo oficial de imprensa, ao passo que a transparência não se satisfaz com o mero cumprimento de formalidades. Ela é mais exigente (GOMES FILHO, 2005, p. 3). "Não basta que as informações estejam disponíveis para haver efetiva transparência; devem estar 'decodificadas' em linguagem acessível" (LOUREIRO; TEIXEIRA; PRADO, 2008, p. 111). Cabe observar não somente o aspecto quantitativo, "mas também o conteúdo oferecido ou sua qualidade, entendida como consistência e inteligibilidade das informações" (LOUREIRO; TEIXEIRA; PRADO, 2008, p. 111).

Ainda que possibilitada pelas modernas tecnologias, a construção de instrumentos de transparência governamental, como é o caso dos websites, "é um processo político que se efetiva no contexto da democratização do país e da necessidade de legitimação política dos governantes" (LOUREIRO; TEIXEIRA; PRADO, 2008, p. 108). Da mesma forma, a institucionalização da transparência governamental depende da inserção do país na economia global e das exigências necessárias ao equilíbrio das contas públicas, sendo requerido também a solvência e credibilidade do governo frente ao mercado financeiro; o que, por sua vez, desencadeia movimentos de reestruturação e modernização do aparato de Estado (LOUREIRO; TEIXEIRA; PRADO, 2008, p. 108).

Alguns estudos já atestaram o pífio desenvolvimento da transparência no cenário brasileiro e creditaram tal desenvolvimento à existência de um sistema formalístico, que serve também para entender o significado dos websites, um instrumento importado de realidades mais desenvolvidas, e que não encontra respaldo nas práticas sociais brasileiras historicamente construídas (RAUPP; PINHO, 2015; RAUPP; PINHO, 2016; JAHNS; RAUPP, 2016; DREHMER; RAUPP, 2019). Seguindo a lógica dos estudos anteriores e sustentado nas

\footnotetext{
${ }^{1}$ São previstas no § 3ㅇ do art. 8ㅇ da Lei n. 12.527, de 18 de novembro de 2011, as seguintes informações: o nome do contratado, o número de sua inscrição na Receita Federal do Brasil, o prazo contratual, o valor e o respectivo processo de contratação ou aquisição.
} 
discussões sobre o formalismo, o objetivo do artigo é analisar o atendimento dos poderes executivos estaduais aos requisitos de transparência nas contratações emergenciais para enfrentamento da COVID-19.

O artigo está estruturado em cinco seções, iniciando por esta introdução. Em seguida são apresentados os fundamentos teóricos que deram sustentação ao objeto de investigação, centrados no formalismo. A terceira seção considera os procedimentos metodológicos adotadas. As duas últimas seções contemplam, respectivamente, os resultados e discussões e as considerações finais do estudo.

\section{O FORMALISMO EXPLICA A TRANSPARÊNCIA NO CONTEXTO BRASILEIRO?}

Ramos (1983) defende, a partir de Riggs (1964), que a sociedade brasileira pode ser explicada segundo o conceito de sociedade prismática, sendo aquela que "apresenta algo grau de heterogeneidade, uma vez que nela coexistem o antigo e o moderno, o atrasado e o avançado, o velho e o novo" (RAMOS, 1983, p. 251). O formalismo, que se apresenta através da discrepância entre as normas prescritas por lei e as atitudes seguidas para sua realização e obediência, foi abordado por Riggs (1964), que alvitrou três tipos de sociedade para defini-lo: sociedades difratadas (países desenvolvidos), sociedades prismáticas (países em desenvolvimento) e sociedades concentradas (países extremamente subdesenvolvidos). 0 formalismo seria residual nos tipos extremos de sociedade e máximo nas prismáticas. A heterogeneidade das sociedades prismáticas se expressa materialmente, entre outras, "sob a forma de mistura de elementos tecnológicos, modernos e antigos, urbanos e rurais" (RAMOS, 1983, p. 251).

Diferentemente das prismáticas, "tanto a sociedade concentrada quanto a difratada apresentam alto grau de homogeneidade, no sentido de que as práticas aí vigentes são mais coerentes" (RAMOS, 1983, p. 251). Motta e Alcadipani (1999) justificam que o formalismo ocorre nas sociedades prismáticas em razão de dependerem das difratadas e serem obrigadas a implementar suas estruturas, isto é, a relação de subjugação das difratadas sobre as prismáticas faz com que as últimas implementem as estruturas da primeira. "O formalismo se dá uma vez que as estruturas das sociedades difratadas não condizem com a realidade cotidiana das prismáticas, sendo que tal incompatibilidade implica a impossibilidade da aplicação total das estruturas implementadas" (MOTTA; ALCADIPANI, 1999, p. 9).

Para Ramos (1983, p. 252) o formalismo é, segundo Riggs (1964), "a discrepância entre a conduta concreta e a norma prescrita que se supõe regulá-la". Quanto maior esta desconexão, mais formalístico o sistema (RIGGS, 1964, p. 123). "Em uma sociedade como a brasileira, fortemente influenciada por padrões ou modelos estrangeiros, torna-se mais fácil adotar uma estrutura formal por decreto ou lei do que institucionalizar o correspondente comportamento social (MACHADO-DA-SILVA et al., 2003).

Aproximando agora de um referencial mais operacional para análise da transparência a partir do formalismo, estudos anteriores já identificaram a influência de um sistema formalístico no raso desenvolvimento da transparência no cenário brasileiro, o que explicaria também a existência de websites como instrumentos importados de realidades mais desenvolvidas, sem respaldo nas práticas sociais brasileiras historicamente enraizadas (RAUPP; PINHO, 2015; RAUPP; PINHO, 2016; JAHNS; RAUPP, 2016; DREHMER; RAUPP, 2019).

Raupp e Pinho (2015) concluíram, a partir de um estudo com o legislativo local, que a entrada em vigor da Lei de Acesso à Informação, por exemplo, parece não ter abalado a ordem existente. Para os autores, se existisse uma cultura política de transparência a lei seria implantada imediatamente. Enfatizam também que mudanças estruturais demandam grande 
Websites dos poderes executivos estaduais e as contratações emergenciais em meio à pandemia da COVID-19: há tecnologia, mas falta transparência

tempo de maturação, e isso no Brasil é sempre demasiado longo. Mesmo que os resultados obtidos não possam ser generalizados, indicam um direcionamento que encontra respaldo em um referencial teórico clássico no Brasil (RAUPP; PINHO, 2015).

Raupp e Pinho (20106), em um outro estudo com o legislativo local, também apontaram que o nível de atendimento às exigências de transparência pode ser explicado por características do formalismo. Além do formalismo, parece ser possível fazer uma reflexão de que a transparência pode ser vista como aquela encontrada em uma sociedade mais desenvolvida, mais participativa, o que não é o caso da sociedade brasileira. Por outro lado, ao incorporar as reflexões de Behn (1998), mostrando as dificuldades de construção e operacionalização da accountability, da qual a transparência é um componente, isto poderia servir de alento, mas também serve de alerta ao ter uma accountability (e mais especificamente transparência) contaminada pelo formalismo, ou seja, traços mais estruturais e resilientes da formação social brasileira.

Jahns e Raupp (2016) trouxeram os resultados com os executivos estaduais para um exame à luz do formalismo, confirmando que o conceito serve para apreender o significado dos websites. Os autores entendem os websites como um instrumento importado de realidades mais desenvolvidas, que são construídos muito mais para constar, para exibir uma adequação à parâmetros de democracias avançadas, mas que na realidade estão longe de efetivamente funcionar, dado que não encontram respaldo nas práticas sociais historicamente construídas pela sociedade brasileira (JAHNS; RAUPP, 2016).

Drehmer e Raupp (2019), em um estudo mais abrangente com os poderes estaduais brasileiros - executivo, legislativo e judiciário - também confirmaram a divergência entre o que está estabelecido no normativo legal e a ocorrência prática, a partir da falta de adequação dos poderes estaduais às exigências de transparência passiva. A postura adotada pelos poderes investigados revelou que o comportamento social ainda não foi institucionalizado, havendo uma defasagem entre a conduta concreta e a norma prescrita. Todavia, segundo já explicitado neste quadro teórico, em se tratando do formalismo trata-se de um processo longo, que envolve questões culturais e de adaptação não só dos poderes estaduais de fornecerem a informação, mas também da sociedade em utilizar o direito de transparência passiva (DREHMER; RAUPP, 2019).

A atualidade de aplicação do conceito de formalismo à explicação do status de construção do exercício da transparência no contexto brasileiro respalda-se em resultados de estudos anteriores (RAUPP; PINHO, 2015; RAUPP; PINHO, 2016; JAHNS; RAUPP, 2016; DREHMER; RAUPP, 2019) que, em síntese, demonstraram, entre outros achados, uma realidade de transparência por meio de websites diversa daquela prescrita nas normas legais (BRASIL, 2000; BRASIL, 2009; BRASIL, 2011), mesmo a legislação citada prevendo sanções em caso de descumprimento. Revela-se pouca transparência diante da tecnologia disponível, mostrando, mais uma vez, que a tecnologia não é o obstáculo para a transparência. Ainda que sejam demandados por exigências legais, os entes estatais descumprem uma sucessão de textos que regulamentam a transparência dos atos governamentais, revelando como a lei, em geral, pode ser descumprida, não levada à sério (RAUPP; PINHO, 2016).

\section{PROCEDIMENTOS METODOLÓGICOS}

Para analisar a transparência dos estados brasileiros nas contratações emergências para enfretamento da COVID-19 foi feita uma pesquisa descritiva, por meio de um estudo documental, predominando a abordagem qualitativa. Na pesquisa descritiva, segundo 
Andrade (2003, p. 124), "os fatos são observados, registrados, analisados, classificados e interpretados, sem que o pesquisador interfira neles". Já a pesquisa documental é aquela que "vale-se de materiais que não receberam nenhum tratamento analítico, ou que ainda podem ser reelaborados de acordo com os objetivos da pesquisa (GIL, 1999, p. 66). Em termos de procedimentos, a abordagem qualitativa se baseia "em dados de texto e imagem, têm passos únicos na análise dos dados e usam estratégias diversas de investigação" (CRESWELL, 2007, p. 185).

Os dados foram obtidos em dois relatórios da Transparência Internacional Brasil sobre - Ranking de transparência no combate à COVID-19. A Transparência Internacional Brasil, como descrito no próprio site, é uma "organização não-governamental apartidária, sem alinhamentos ideológicos, sem fins lucrativos, dedicada à luta contra a corrupção", e está no Brasil desde 2016 (2020d). Um dos relatórios utilizados descreve as notas metodológicas do ranking. O outro relatório, na forma de planilha eletrônica, apresenta os dados detalhados do modelo de análise (Quadro 1) obtidos com estados e capitais e divulgados pela organização em 21 de maio de 2020. O estudo se concentrou nos dados dos estados.

\begin{tabular}{|c|c|c|c|}
\hline Dimensão & Categoria & Item & Pontuação \\
\hline \multirow{13}{*}{ 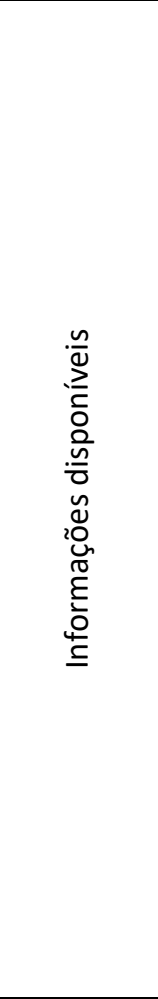 } & \multirow{6}{*}{$\begin{array}{l}\text { Informações } \\
\text { essenciais } \\
\text { (peso 4) }\end{array}$} & $\begin{array}{l}\text { Site específico para informações sobre } \\
\text { contratações emergenciais }\end{array}$ & $\begin{array}{l}1 \text { (existe portal específico); } 0.5 \\
\text { (existe destaque, aba ou botão } \\
\text { em portal já existente); } 0 \text { (não há } \\
\text { site específico) }\end{array}$ \\
\hline & & Nome do/a contratado/a & 1 (existe); 0 (não existe) \\
\hline & & Número do CPF ou CNPJ & 1 (existe); 0 (não existe) \\
\hline & & Valor total e unitário & $\begin{array}{l}1 \text { (valor unitário e total); } 0.5 \\
\text { (apenas valor total); } 0 \text { (não } \\
\text { existe) }\end{array}$ \\
\hline & & Prazo contratual & 1 (existe); 0 (não existe) \\
\hline & & Processo de contratação ou aquisição & $\begin{array}{l}1 \text { (no e íntegra do processo); } 0.5 \\
\text { (apenas no do processo); } 0 \text { (não } \\
\text { existe) }\end{array}$ \\
\hline & \multirow{7}{*}{$\begin{array}{l}\text { Informações } \\
\text { desejáveis } \\
\text { (peso 2) }\end{array}$} & Data de celebração do contrato & 1 (existe); 0 (não existe) \\
\hline & & Órgão contratante & 1 (existe); 0 (não existe) \\
\hline & & Quantidade & 1 (existe); 0 (não existe) \\
\hline & & Descrição do bem ou serviço & 1 (existe); 0 (não existe) \\
\hline & & Local da execução & 1 (existe); 0 (não existe) \\
\hline & & $\begin{array}{l}\text { Publicação do edital e fases públicas das } \\
\text { licitações na modalidade pregão no } \\
\text { mesmo portal das contratações } \\
\text { emergenciais }\end{array}$ & 1 (existe); 0 (não existe) \\
\hline & & Forma / modalidade da contratação & 1 (existe); 0 (não existe) \\
\hline \multirow{5}{*}{ 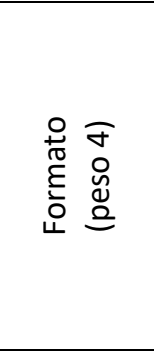 } & \multirow{5}{*}{$\begin{array}{l}\text { Dados } \\
\text { abertos }\end{array}$} & Formato aberto dos dados & 1 (existe); 0 (não existe) \\
\hline & & $\begin{array}{l}\text { Possibilidade de download das } \\
\text { informações }\end{array}$ & 1 (disponível); 0 (não disponível) \\
\hline & & Mecanismos de busca & 1 (existe); 0 (não existe) \\
\hline & & $\begin{array}{l}\text { Possibilidade de download da íntegra do } \\
\text { contrato }\end{array}$ & $\begin{array}{l}1 \text { (disponível em formato aberto); } \\
0.5 \text { (apenas em PDF); } 0 \text { (não } \\
\text { disponível) }\end{array}$ \\
\hline & & Dicionário de dados & 1 (existe); 0 (não existe) \\
\hline \multirow{2}{*}{ 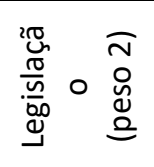 } & $\begin{array}{l}\text { Legislação } \\
\text { específica }\end{array}$ & $\begin{array}{l}\text { Há legislação específica tratando de } \\
\text { contratações emergenciais? }\end{array}$ & 1 (existe); 0 (não existe) \\
\hline & $\begin{array}{l}\text { Divulgação de } \\
\text { legislação }\end{array}$ & $\begin{array}{l}\text { A legislação aplicável às contratações } \\
\text { emergenciais está disponível no mesmo }\end{array}$ & 1 (sim); 0 (não) \\
\hline
\end{tabular}


Websites dos poderes executivos estaduais e as contratações emergenciais em meio à pandemia da COVID-19: há tecnologia, mas falta transparência

\begin{tabular}{|c|c|c|c|}
\hline & & portal? & \\
\hline & Controle & $\begin{array}{l}\text { Há previsão legal de que as contratações } \\
\text { sejam acompanhadas pelos órgãos de } \\
\text { controle? }\end{array}$ & $\begin{array}{l}1 \text { (previsto em legislação ou atos } \\
\text { oficiais); } 0.5 \text { (notícia); } 0 \text { (não) }\end{array}$ \\
\hline & $\begin{array}{l}\text { Informações } \\
\text { aos gestores }\end{array}$ & $\begin{array}{l}\text { São fornecidas informações e orientações } \\
\text { aos gestores responsáveis por } \\
\text { contratações? }\end{array}$ & 1 (sim); 0 (não) \\
\hline & $\begin{array}{l}\text { Repositório } \\
\text { de legislação }\end{array}$ & $\begin{array}{l}\text { Há um repositório com a legislação } \\
\text { dedicada ao enfrentamento da COVID- } \\
19 ?\end{array}$ & 1 (existe); 0 (não existe) \\
\hline \multirow{11}{*}{ 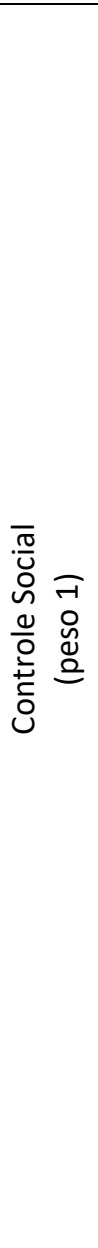 } & \multirow{4}{*}{$\begin{array}{l}\text { Destaque } \\
\text { para } \\
\text { informações } \\
\text { sobre as } \\
\text { contratações } \\
\text { Emergenciais } \\
\text { no: }\end{array}$} & Portal oficial do governo & 1 (existe); 0 (não existe) \\
\hline & & $\begin{array}{l}\text { Portal de informação sobre a COVID-19 } \\
\text { ou do órgão de saúde responsável }\end{array}$ & 1 (existe); 0 (não existe) \\
\hline & & $\begin{array}{l}\text { Portal de transparência ou do órgão de } \\
\text { controle }\end{array}$ & 1 (existe); 0 (não existe) \\
\hline & & $\begin{array}{l}\text { Redes sociais do governo (perfis oficiais } \\
\text { dos governos municipais/estaduais no } \\
\text { Facebook e Twitter) }\end{array}$ & $\begin{array}{l}1 \text { (existe entre as publicações dos } \\
\text { sete dias anteriores à avaliação, } \\
\text { no Facebook e Twitter); } 0.5 \\
\text { (existe entre as publicações dos } \\
\text { sete dias anteriores à avaliação, } \\
\text { no Facebook ou Twitter); } 0 \text { (não } \\
\text { existe ou publicação anterior ao } \\
\text { período considerado) }\end{array}$ \\
\hline & \multirow{3}{*}{ Ouvidoria } & $\begin{array}{l}\text { Link para Ouvidoria no portal onde estão } \\
\text { as contratações emergenciais }\end{array}$ & 1 (existe); 0 (não existe) \\
\hline & & $\begin{array}{l}\text { Possibilidade de se realizar denúncia } \\
\text { anônima }\end{array}$ & 1 (sim); 0 (não) \\
\hline & & $\begin{array}{l}\text { Tag específica em assunto para 'COVID- } \\
19^{\prime}\end{array}$ & 1 (sim); 0 (não) \\
\hline & \multirow{3}{*}{$\begin{array}{l}\text { Transparência } \\
\text { Passiva }\end{array}$} & $\begin{array}{l}\text { Link para o E-sic no portal onde estão as } \\
\text { contratações emergenciais }\end{array}$ & 1 (existe); 0 (não existe) \\
\hline & & $\begin{array}{l}\text { Possibilidade de se realizar pedido de } \\
\text { acesso à informação de forma sigilosa }\end{array}$ & 1 (sim); 0 (não) \\
\hline & & $\begin{array}{l}\text { Tag específica em assunto para 'COVID- } \\
19^{\prime}\end{array}$ & 1 (sim); 0 (não) \\
\hline & $\begin{array}{l}\text { Órgão } \\
\text { coletivo }\end{array}$ & $\begin{array}{l}\text { Acompanhamento por conselho, } \\
\text { comissão ou outro órgão com } \\
\text { participação de organizações da } \\
\text { sociedade civil }\end{array}$ & 1 (existe); 0 (não existe) \\
\hline
\end{tabular}

Fonte: Transparência Internacional Brasil (2020a, p. 3-6)

O modelo de análise da Transparência Internacional Brasil considera 4 dimensões: Informações disponíveis, sendo as informações essenciais - Lei № 13.979/2020, art. 4, §2ㅇ com peso 4, e as informações desejáveis com peso 2; Formato das informações com peso 4; Legislação com peso 2; e Controle social com peso 1 . O fato de o modelo extrapolar questões legais pode torná-lo muito exigente. Entretanto, e esta é a ideia do artigo, não se deve enxergar a transparência apenas como uma exigência legal, mas, sobretudo, enquanto um valor fundamental.

\section{RESULTADOS E DISCUSSÕES}

Os dados utilizados como ponto de partida para as análises são apresentados na Tabela 1. Nela é identificada a pontuação por item, a pontuação final e o respectivo nível de transparência dos poderes executivos estaduais no ranking. 
Fabiano Maury Raupp e José Antonio Gomes De Pinho

Tabela 1 - Ranking de transparência em contratações emergenciais nos Estados

\begin{tabular}{|c|c|c|c|c|c|c|c|c|c|c|c|c|c|c|c|c|c|c|c|c|c|c|c|c|c|c|c|c|c|c|c|c|c|c|c|}
\hline \multirow[b]{3}{*}{ Capitais } & \multicolumn{13}{|c|}{ Informações Disponíveis } & \multicolumn{5}{|c|}{ Formato } & \multicolumn{5}{|c|}{ Legislação } & \multicolumn{11}{|c|}{ Controle Social } & \multirow{3}{*}{ 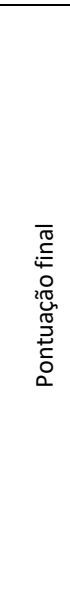 } \\
\hline & \multicolumn{6}{|c|}{ 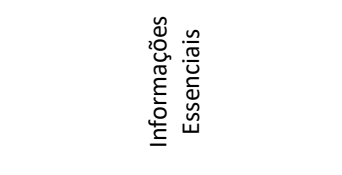 } & \multicolumn{7}{|c|}{ 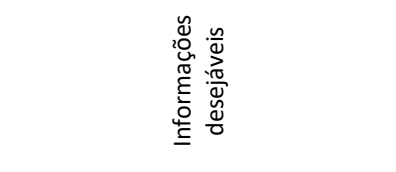 } & \multicolumn{5}{|c|}{ 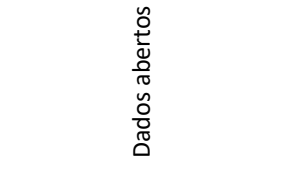 } & \multirow{2}{*}{\multicolumn{2}{|c|}{ 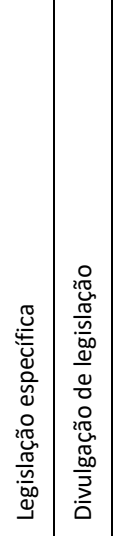 }} & \multirow{2}{*}{\multicolumn{2}{|c|}{ 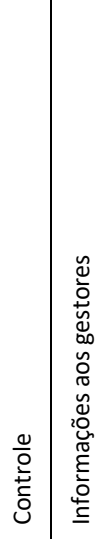 }} & \multirow[b]{2}{*}{ 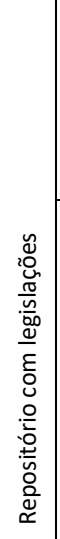 } & \multicolumn{4}{|c|}{ 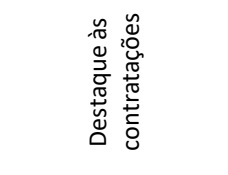 } & \multicolumn{3}{|c|}{ 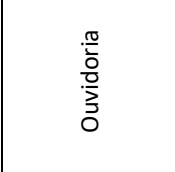 } & \multicolumn{3}{|c|}{ 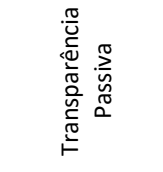 } & 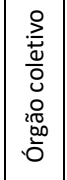 & \\
\hline & 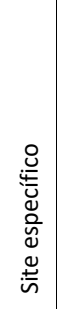 & 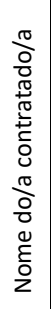 & 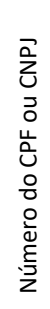 & 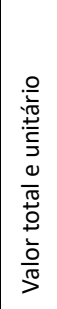 & 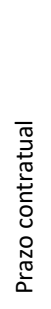 & 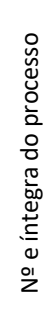 & 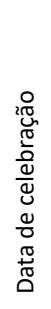 & 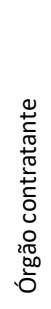 & 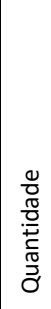 & 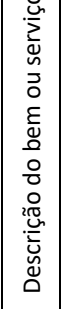 & 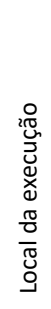 & 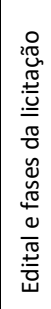 & 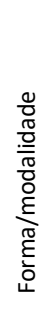 & 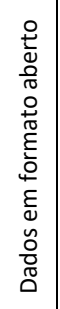 & $\begin{array}{l}0 \\
8 \\
0 \\
\frac{0}{5} \\
0 \\
0\end{array}$ & 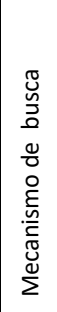 & 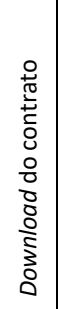 & 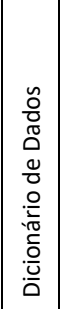 & & & & & & 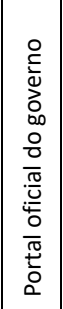 & $\begin{array}{l}\overrightarrow{0} \\
\stackrel{0}{0} \\
\frac{0}{\pi} \\
\frac{0}{0} \\
0\end{array}$ & 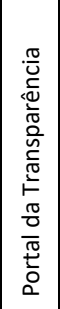 & 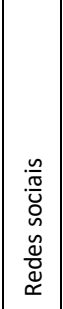 & 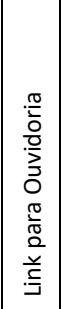 & 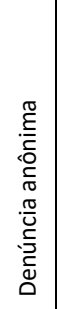 & 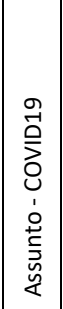 & 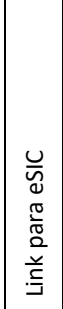 & 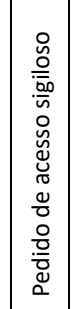 & 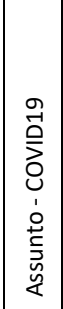 & 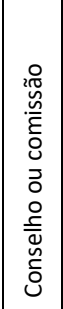 & \\
\hline Espírito Santo & 1 & 1 & 1 & 1 & 1 & 1 & 1 & 1 & 1 & 1 & 0 & 1 & 1 & 1 & 1 & 1 & 1 & 1 & 1 & 1 & 1 & 1 & 1 & 1 & 1 & 1 & 1 & 1 & 1 & 1 & 1 & 1 & 1 & 1 & 97,47 \\
\hline Distrito Federal & 1 & 1 & 1 & 1 & 1 & 0,5 & 1 & 1 & 1 & 1 & 0 & 0 & 1 & 1 & 1 & 1 & 1 & 1 & 1 & 1 & 1 & 1 & 1 & 1 & 1 & 1 & 0 & 1 & 1 & 1 & 1 & 0 & 0 & 1 & 88,61 \\
\hline Goiás & 0,5 & 1 & 1 & 1 & 1 & 0,5 & 1 & 1 & 1 & 1 & 0 & 1 & 1 & 1 & 1 & 1 & 1 & 1 & 1 & 0 & 1 & 0 & 1 & 1 & 1 & 1 & 0 & 1 & 1 & 1 & 1 & 1 & 1 & 0 & 84,81 \\
\hline Paraná & 1 & 1 & 1 & 1 & 1 & 0,5 & 1 & 1 & 1 & 1 & 0 & 1 & 1 & 1 & 1 & 1 & 0,5 & 0 & 1 & 1 & 1 & 1 & 1 & 1 & 1 & 1 & 0 & 1 & 1 & 0 & 1 & 0 & 0 & 0 & 81,01 \\
\hline Ceará & 0,5 & 1 & 1 & 0,5 & 0 & 1 & 0 & 1 & 0 & 1 & 0 & 1 & 1 & 1 & 1 & 0 & 1 & 1 & 1 & 1 & 1 & 1 & 1 & 1 & 1 & 1 & 1 & 1 & 1 & 0 & 1 & 1 & 0 & 0 & 73,42 \\
\hline Maranhão & 0,5 & 1 & 1 & 1 & 1 & 0,5 & 1 & 1 & 1 & 1 & 1 & 0 & 1 & 1 & 1 & 1 & 0,5 & 1 & 0 & 0 & 1 & 0 & 1 & 0 & 0 & 1 & 0 & 1 & 0 & 1 & 1 & 0 & 0 & 0 & 73,42 \\
\hline Rondônia & 0,5 & 1 & 1 & 0,5 & 0 & 0,5 & 1 & 1 & 0 & 1 & 0 & 1 & 1 & 0 & 1 & 1 & 0,5 & 1 & 1 & 1 & 1 & 1 & 1 & 1 & 1 & 1 & 0,5 & 1 & 1 & 1 & 1 & 0 & 1 & 0 & 71,52 \\
\hline Santa Catarina & 1 & 1 & 1 & 0,5 & 1 & 0,5 & 1 & 1 & 0 & 1 & 1 & 0 & 1 & 1 & 1 & 1 & 0,5 & 0 & 1 & 0 & 0 & 1 & 1 & 0 & 0 & 0 & 0 & 1 & 1 & 0 & 1 & 0 & 0 & 0 & 67,09 \\
\hline Paraíba & 1 & 1 & 1 & 0,5 & 1 & 0,5 & 1 & 1 & 0 & 1 & 0 & 0 & 0 & 1 & 1 & 1 & 0 & 0 & 1 & 1 & 1 & 1 & 1 & 1 & 1 & 1 & 0 & 0 & 0 & 0 & 1 & 0 & 0 & 0 & 65,82 \\
\hline Amazonas & 0,5 & 1 & 1 & 0,5 & 1 & 1 & 0 & 0 & 0 & 1 & 0 & 1 & 1 & 1 & 1 & 1 & 0,5 & 0 & 1 & 0 & 1 & 0 & 1 & 0 & 0 & 1 & 0 & 0 & 1 & 1 & 1 & 0 & 0 & 0 & 63,29 \\
\hline Mato Grosso & 1 & 1 & 1 & 0,5 & 1 & 0 & 0 & 1 & 0 & 1 & 0 & 1 & 0 & 1 & 1 & 1 & 0,5 & 0 & 1 & 0 & 0 & 1 & 1 & 0 & 0 & 1 & 0 & 1 & 1 & 0 & 1 & 1 & 0 & 0 & 62,03 \\
\hline Minas Gerais & 0,5 & 1 & 1 & 0,5 & 1 & 0,5 & 0 & 1 & 0 & 1 & 0 & 0 & 0 & 1 & 1 & 0 & 0,5 & 1 & 1 & 0 & 1 & 1 & 1 & 0 & 0 & 1 & 1 & 0 & 1 & 1 & 0 & 0 & 0 & 1 & 62,03 \\
\hline Mato Gross do Sul & 1 & 1 & 1 & 0,5 & 1 & 0,5 & 0 & 1 & 0 & 1 & 0 & 0 & 0 & 1 & 1 & 1 & 0 & 0 & 1 & 1 & 1 & 1 & 1 & 0 & 1 & 0 & 0 & 0 & 1 & 0 & 0 & 0 & 0 & 0 & 60,76 \\
\hline Pernambuco & 1 & 1 & 0 & 1 & 0 & 0 & 0 & 1 & 1 & 1 & 0 & 1 & 1 & 1 & 1 & 0 & 0 & 0 & 1 & 1 & 1 & 1 & 1 & 0 & 1 & 1 & 0 & 1 & 1 & 1 & 1 & 0 & 0 & 0 & 58,23 \\
\hline Amapá & 0,5 & 1 & 1 & 0,5 & 0 & 0,5 & 1 & 1 & 1 & 1 & 0 & 0 & 1 & 0 & 1 & 1 & 0,5 & 0 & 1 & 1 & 0 & 0 & 1 & 0 & 1 & 1 & 0 & 1 & 1 & 0 & 1 & 0 & 0 & 0 & 56,96 \\
\hline Tocantins & 0,5 & 1 & 1 & 0,5 & 1 & 0,5 & 1 & 1 & 1 & 1 & 0 & 1 & 1 & 0 & 0 & 1 & 0,5 & 0 & 1 & 0 & 0 & 1 & 1 & 0 & 0 & 1 & 0 & 1 & 1 & 0 & 0 & 0 & 0 & 0 & 56,96 \\
\hline Bahia & 1 & 1 & 1 & 0,5 & 1 & 0,5 & 0 & 0 & 0 & 1 & 0 & 0 & 0 & 0 & 0 & 1 & 0,5 & 0 & 1 & 1 & 1 & 1 & 1 & 0 & 1 & 0 & 0 & 1 & 1 & 0 & 1 & 1 & 0 & 0 & 54,43 \\
\hline $\begin{array}{l}\text { Piauí } \\
\end{array}$ & 1 & 1 & 1 & 0,5 & 1 & 0,5 & 1 & 1 & 0 & 1 & 0 & 0 & 1 & 0 & 0 & 1 & 0 & 0 & 0 & 0 & 1 & 1 & 1 & 0 & 0 & 1 & 0 & 1 & 1 & 0 & 1 & 0 & 0 & 0 & 53,16 \\
\hline Alagoas & 0,5 & 1 & 1 & 0,5 & 0 & 0,5 & 0 & 1 & 0 & 1 & 0 & 0 & 0 & 1 & 1 & 1 & 0 & 0 & 1 & 1 & 0 & 0 & 1 & 1 & 1 & 1 & 0 & 0 & 1 & 0 & 1 & 0 & 0 & 0 & 51,90 \\
\hline Rio Grande do Sul & 0,5 & 1 & 1 & 0,5 & 1 & 0,5 & 1 & 1 & 0 & 1 & 0 & 0 & 1 & 0 & 0 & 1 & 0,5 & 0 & 1 & 0 & 0 & 1 & 1 & 0 & 0 & 0 & 0 & 1 & 1 & 0 & 1 & 0 & 0 & 0 & 51,90 \\
\hline Rio Grande do Norte & 0,5 & 1 & 1 & 0,5 & 1 & 0,5 & 0 & 1 & 0 & 1 & 0 & 0 & 0 & 0 & 0 & 0 & 1 & 0 & 1 & 1 & 0 & 0 & 1 & 0 & 0 & 1 & 0 & 1 & 1 & 1 & 1 & 0 & 0 & 0 & 46,84 \\
\hline Sergipe & 1 & 1 & 1 & 0,5 & 1 & 0,5 & 0 & 0 & 0 & 1 & 0 & 0 & 1 & 0 & 0 & 0 & 1 & 0 & 0 & 0 & 0 & 0 & 1 & 1 & 1 & 1 & 0 & 0 & 1 & 1 & 0 & 0 & 1 & 0 & 45,57 \\
\hline Pará & 1 & 1 & 0 & 0,5 & 0 & 0,5 & 1 & 1 & 0 & 1 & 0 & 0 & 1 & 0 & 0 & 1 & 0 & 0 & 1 & 0 & 0 & 1 & 1 & 1 & 1 & 0 & 0 & 1 & 1 & 0 & 1 & 0 & 0 & 0 & 44,30 \\
\hline Rio de Janeiro & 1 & 0 & 0 & 0 & 1 & 0,5 & 1 & 1 & 0 & 1 & 0 & 0 & 1 & 1 & 1 & 0 & 0 & 0 & 1 & 0 & 0,5 & 0 & 1 & 1 & 0 & 1 & 0 & 0 & 1 & 1 & 0 & 0 & 0 & 0 & 44,30 \\
\hline Acre & 1 & 1 & 1 & 0,5 & 0 & 0 & 1 & 0 & 1 & 1 & 0 & 0 & 1 & 0 & 0 & 0 & 0 & 0 & 1 & 0 & 1 & 1 & 1 & 1 & 1 & 0 & 0 & 0 & 0 & 0 & 0 & 1 & 0 & 0 & 41,77 \\
\hline São Paulo & 1 & 1 & 1 & 0 & 0 & 0,5 & 0 & 0 & 0 & 1 & 0 & 0 & 0 & 0 & 0 & 0 & 0 & 0 & 0 & 0 & 0 & 0 & 1 & 0 & 1 & 1 & 0 & 1 & 0 & 0 & 1 & 0 & 0 & 0 & 27,85 \\
\hline Roraima & 0,5 & 0 & 0 & 0 & 0 & 0 & 0 & 0 & 0 & 0 & 0 & 1 & 0 & 0 & 0 & & 0 & 0 & 1 & 0 & 1 & & 1 & 0 & 0 & & 0,5 & 1 & 1 & 1 & 1 & 0 & 0 & 0 & 22,15 \\
\hline
\end{tabular}

Fonte: Transparência Internacional Brasil (2020b).

RGO - Revista Gestão Organizacional, Chapecó, v. 14, n. 1, p. 416-428, jan./abr. 2021. 
Websites dos poderes executivos estaduais e as contratações emergenciais em meio à pandemia da COVID-19: há tecnologia, mas falta transparência

Analisando os dados com um olhar mais detalhado, na dimensão Informações disponiveis vê-se que nem todos os poderes executivos atenderam de forma satisfatória à categoria informações essenciais, mesmo sendo necessariamente decorrente de exigências legais (Lei n. 13.979/2020, art. 4, §2ㅇ). Nesta categoria os itens mais atendidos foram nome do/a contratado/a, número do CPF ou CNPJ, e site específico para informações sobre contratações emergenciais. Ainda assim, há itens que poderiam ter sua adesão melhorada, considerados tecnicamente de fácil disponibilização no website, como é o caso do processo de contratação ou aquisição (número e íntegra do processo). O Estado do Espírito Santo gabaritou todos os itens, demonstrando pleno atendimento aos requisitos. No outro extremo Roraima apresentou o pior desempenho nesta categoria.

Na mesma dimensão, a categoria informações desejáveis - no geral - recebeu um atendimento inferior em relação à anterior. Também era de pressupor, como estamos aqui tratando de informações que extrapolam as exigências legais, que o atendimento seria menor. Os itens mais atendidos foram descrição do bem ou serviço e órgão contratante. Já o item menos atendido foi a informação sobre o local de execução. Os demais itens ficaram em níveis intermediários de atendimento. De forma semelhante à categoria anterior, os itens com menor "adesão" não requerem atividades complexas para que possam ser disponibilizados, ou seja, os poderes executivos que ainda não atendem poderiam facilmente fazer este ajuste. Os Estados que mais atenderam aos itens foram Espírito Santo, Goiás, Paraná, Maranhão e Tocantins. Já os Estados que menos atenderam foram Bahia, São Paulo e Roraima.

Na dimensão Formato das informações - e em sua única categoria Dados abertos observou-se um dos piores desempenhos do levantamento. O peso da dimensão recebido no modelo de análise demonstra que a forma como os dados são disponibilizados é determinante para possibilitar a análise das contratações emergenciais e, consequentemente, potencializar a sua transparência, mas esta não foi uma realidade encontrada nos poderes executivos estaduais. Mecanismo de busca foi o item mais disponibilizado nos websites, e dicionário de dados foi o menos encontrado. Os Estados do Espírito Santo, Distrito Federal e Goiás apresentaram todos os itens da categoria/dimensão. No outro extremo, Acre, São Paulo e Roraima não apresentaram nenhum item da categoria/dimensão.

A dimensão Legislação, formada por cinco categorias, obteve níveis de atendimento diferentes entre os poderes executivos estaduais. A existência de um repositório com a legislação dedicada ao enfrentamento da COVID-19 foi verificada em todos os poderes executivos. Entre os itens menos atendidos, a divulgação de legislação aplicável às contratações emergenciais no mesmo portal foi verificada em apenas 12 websites. Embora cada categoria traga individualmente sua contribuição à construção da transparência, tornase também importante a sinergia entre elas, representada, por exemplo, pela concentração de todos os itens no mesmo portal das contratações, facilitando o acesso às informações. Os Estados do Espírito Santo, Distrito Federal, Paraná, Rondônia, Paraíba, Mato Grosso do Sul, Pernambuco e Bahia atenderam a todos os itens da dimensão. Por outro lado, São Paulo e Sergipe foram os estados menos pontuados.

$\mathrm{Na}$ última dimensão do modelo de análise, o Controle Social restou também entre as dimensões com o menor desempenho. Ressalva-se que o não atendimento aos itens desta dimensão tenderia a não impactar na classificação do estado na mesma proporção dos itens das dimensões anteriores, uma vez que esta dimensão tem peso 1 no computo do resultado final. Mesmo com o menor peso, o controle social é essencial e decisivo na construção de condições de transparência. As categorias mais atendidas foram destaque para informações 
sobre as contratações emergenciais no portal e ouvidoria. As categorias menos presentes foram transparência passiva e possibilidade de acompanhamento por conselho, comissão ou outro órgão com participação de organizações da sociedade civil. O Estado do Espírito Santo uma vez mais gabaritou todos os itens, no lado oposto Mato Grosso do Sul teve o pior desempenho. Saindo de uma análise detalhada e entrando em um quadro mais geral, na Tabela 2 é apresentada a síntese da transparência dos poderes executivos nas contratações emergenciais.

Tabela 2 - Transparência dos poderes executivos nas contratações emergenciais

\begin{tabular}{l|l|c|c}
\multicolumn{1}{c|}{ Nível } & \multicolumn{1}{c|}{ Estados } & Quantidade & Percentual \\
\hline Ótimo & Distrito Federal, Espírito Santo, Goiás, Paraná & 4 & $14,81 \%$ \\
\hline Bom & $\begin{array}{l}\text { Amazonas, Ceará, Maranhão, Mato Grosso do Sul, Mato Grosso, Minas } \\
\text { Gerais, Paraíba, Rondônia, Santa Catarina }\end{array}$ & 9 & $33,33 \%$ \\
\hline Regular & $\begin{array}{l}\text { Acre, Alagoas, Amapá, Bahia, Pará, Pernambuco, Piauí, Rio de Janeiro, } \\
\text { Rio Grande do Norte, Rio Grande do Sul, Sergipe, Tocantins }\end{array}$ & 12 & $44,44 \%$ \\
\hline Ruim & São Paulo, Roraima & 2 & $7,42 \%$ \\
\hline Péssimo & - & 0 & $0,00 \%$ \\
\hline Total & & 27 & $100,00 \%$ \\
\hline
\end{tabular}

Nota: Níveis de transparência: péssimo (0 - 19); ruim (20 - 39); regular (40 - 59); bom (60 - 79); ótimo (80 - 100$)$.

Fonte: elaborada a partir dos dados da Transparência Internacional Brasil (2020b).

Somadas as quantidades de estados nos níveis regular e ruim, é possível perceber que a maioria dos poderes executivos apresenta níveis insuficientes de transparência $(51,86 \%)$. Estes resultados seriam explicados, principalmente, pelo desempenho nas dimensões Informações disponíveis (categoria informações desejáveis) e Formato das informações. A constância dos estados nas melhores e piores posições por dimensão confirma o resultado, como pode ser observado em relação ao Estado do Espírito Santo que esteve sempre presente nas primeiras posições, e o Estado de Roraima que esteve em último em duas dimensões.

Oportuno observar um outro ranking de transparência na COVID-19 que já vem sendo realizado pela Open Knowledge Brasil (OKBR), também conhecida como Rede pelo Conhecimento Livre. A OKBR é uma organização da sociedade civil sem fins lucrativos e apartidária que atua no país desde 2013. Desenvolve e incentiva o uso de tecnologias cívicas e de dados abertos, realizando análises de políticas públicas e promovendo o conhecimento livre para tornar a relação entre governo e sociedade mais transparente e participativa (https://www.ok.org.br/). Dentre as ações, elaborou o Índice de Transparência da COVID-19, um indicador sintético composto por três dimensões: Conteúdo, Granularidade e Formato. $\mathrm{O}$ resumo do levantamento divulgado pela organização em 21 de maio de 2020 é apresentado na Tabela 3.

Tabela 3 - Transparência dos poderes executivos sobre a COVID-19

\begin{tabular}{l|l|c|c}
\hline Nível & \multicolumn{1}{|c|}{ Estados } & Quantidade & Percentual \\
\hline \multirow{2}{*}{ Alto } & $\begin{array}{l}\text { Acre, Alagoas, Amapá, Ceará, Distrito Federal, Espírito Santo, Goiás, } \\
\text { Minas Gerais, Pará, Paraíba, Paraná, Pernambuco, Piauí, Rio Grande do } \\
\text { Norte, Rondônia, Santa Catarina, Sergipe }\end{array}$ & 17 & $62,97 \%$ \\
\hline Bom & Amazonas, Maranhão, Rio de Janeiro, São Paulo & 4 & $14,81 \%$ \\
\hline Médio & Bahia, Mato Grosso, Rio Grande do Sul, Roraima, Tocantins & 5 & $18,52 \%$ \\
\hline Baixo & Mato Grosso do Sul & 1 & $3,70 \%$ \\
\hline Opaco & - & 0 & $0,00 \%$ \\
\hline \multicolumn{2}{l}{ Total } & 27 & $100,00 \%$ \\
\hline
\end{tabular}

Nota: Níveis de transparência: opaco (0 - 19); baixo (20 - 39); médio (40 - 59); bom (60 - 79); alto (80 - 100).

Fonte: elaborada a partir dos dados da OKBR (2020). 
Websites dos poderes executivos estaduais e as contratações emergenciais em meio à pandemia da COVID-19: há tecnologia, mas falta transparência

Embora o ranking da Transparência Internacional Brasil seja específico para contratos emergenciais, há pontos em comum ao ranking da OKBR, tanto em termos de dimensões do modelo de análise quanto nos intervalos de pontuação. Obviamente que a situação apresentada pela OKBR se mostra mais alvissareira - 77,78 \% dos estados se encontra nos níveis alto e bom -, e isto pode ser explicado, possivelmente, de fato de ser o oitavo ranking realizado pela OKBR, ou seja, alguns estados podem ter aprendido e aperfeiçoado a transparência a partir dos primeiros rankings.

Ao resgatarmos fragmentos do processo de construção de normativos legais sobre a transparência no contexto brasileiro, é possível verificar que a Lei Complementar n. 101, de 04 de maio de 2000 - Lei de Responsabilidade Fiscal - já definia "meios eletrônicos de acesso público" para divulgação de informações sobre a transparência da gestão fiscal. Ratificaram e ampliaram tais exigências a Lei Complementar n. 131, de 27 de maio de 2009 - Lei da Transparência - e a Lei n. 12.527, de 18 de novembro de 2011 - Lei de Acesso à Informação . Ou seja, passados 20 anos a transparência de informações públicas ainda não é um fato, aquilo que Raupp e Pinho (2015) já tratavam como uma mudança estrutural e que no caso brasileiro normalmente requer um tempo descomedidamente longo de maturação.

Os resultados aqui obtidos representam ecos de estudos anteriores. Assim como no estudo de Raupp e Pinho (2015), entende-se que o formalismo serve para apreender o significado dos websites na promoção da transparência sobre as contratações emergenciais, considerado um instrumento importado de realidades mais desenvolvidas, mas que na verdade não encontra respaldo nas práticas sociais brasileiras construídas. "Isto não quer dizer que não sejam alcançados alguns resultados ou que se adote uma posição fatalista de que "nunca chegaremos lá"” (RAUPP; PINHO, 2015, p. 43). Cabível também destacar que os poderes executivos estaduais aderem, quando muito, as exigências da lei em geral. "A lei pesa como a espada de Dâmocles e, bem ou mal, tenta-se o seu atendimento. Mas, o que não consta da lei, o que deriva da iniciativa da sociedade civil pode ser visto um trabalho extra, adicional que esses entes estatais tentariam evitar" (RAUPP; PINHO, 2016, p. 297).

Os estados atendem aos requisitos mínimos do modelo de análise, porém sem evidente busca por inovações ou formas de melhor atender às necessidades da sociedade quanto à transparência das contratações emergenciais na COVID-19. "Ir além das exigências legais e do mínimo exigido é o que se espera dos entes federados, buscando sempre maior interação e disponibilização das informações para seus usuários, os cidadãos" (JAHNS; RAUPP, 2016, p. 69). Segundo colocado no quadro teórico, este é um processo longo, que envolve questões culturais e de adaptação de ambos os lados: os poderes executivos estaduais que devem ser transparentes, e a sociedade que deve fazer valer seus direitos de utilizar a transparência e exercer o controle social, promovendo a accountability (DREHMER; RAUPP, 2019).

\section{CONSIDERAÇÕES FINAIS, LIMITAÇÕES E SUGESTÕES DE ESTUDOS FUTUROS}

O objetivo do estudo foi analisar o atendimento dos poderes executivos estaduais aos requisitos de transparência nas contratações emergenciais para enfrentamento da COVID-19. Fez-se uma pesquisa descritiva, por meio de um estudo documental, predominando a abordagem qualitativa. Os dados foram obtidos a partir de relatórios da Transparência Internacional Brasil, e analisados à luz do formalismo. O fato de o modelo extrapolar questões legais pode torná-lo muito exigente. Entretanto, e esta é a ideia do artigo, não se deve 
enxergar a transparência apenas como uma exigência legal, mas, sobretudo, enquanto um valor fundamental.

Ainda que a tecnologia exista, e em abundância, falta transparência nos websites dos poderes executivos estaduais. Os websites existem e alguns itens por demanda legal são atendidos, entretanto, à medida que avança para outros itens/categorias/dimensões que extrapolam a exigência legal, vê-se uma contribuição cada vez menor para a construção do exercício da transparência nas contratações emergenciais. Neste ponto, quadro teórico do formalismo parece oportuno para fundamentar os dados analisados. Em uma perspectiva pessimista, os resultados revelariam um cenário pouco animador. Por outro lado, em uma perspectiva realista, de como funcionam as estruturas no Brasil, os resultados podem indicar a existência de um movimento para construção de condições de transparência.

Em termos de limitações, entende-se que as considerações da pesquisa não podem ser generalizadas aos websites de outras esferas: federal e municipal. Outra limitação diz respeito à velocidade das mudanças das tecnologias de informação, consequentemente das informações disponibilizadas nos websites. Os dados obtidos representam a realidade de uma primeira coleta realizada. Estudos futuros em outras esferas e com outros olhares, por exemplo, objetivando identificar os fatores que explicam a capacidade dos poderes executivos estaduais na construção de transparência das contratações emergenciais, são incentivadas, o que consentirá uma melhor compreensão desta temática.

\section{REFERÊNCIAS}

ANDRADE, M. M. de. Introdução à metodologia do trabalho científico. São Paulo: Atlas, 2003.

BEHN, R. D. O novo paradigma da gestão pública e a busca da accountability democrática. Revista do Serviço Público, Brasília, ano 49, n. 4, p. 5-45, out./dez., 1998. DOI: https://doi.org/10.21874/rsp.v49i4.399.

BRASIL. Lei Complementar n. 101, de 04 de maio de 2000. Estabelece normas de finanças públicas voltadas para a responsabilidade na gestão fiscal e dá outras providências. Disponível em: http://www.planalto.gov.br/ccivil_03/leis/lcp/lcp101.htm. Acesso em: 23 maio 2020.

BRASIL. Lei Complementar n. 131, de 27 de maio de 2009. Acrescenta dispositivos à Lei Complementar $n^{\circ} 101$, de 4 de maio de 2000, que estabelece normas de finanças públicas voltadas para a responsabilidade na gestão fiscal e dá outras providências, a fim de determinar a disponibilização, em tempo real, de informações pormenorizadas sobre a execução orçamentária e financeira da União, dos Estados, do Distrito Federal e dos Municípios. Disponível em: http://www.planalto.gov.br/ccivil_03/leis/lcp/lcp131.htm. Acesso em: 23 maio 2020.

BRASIL. Lei n. 12.527, de 18 de novembro de 2011. Regula o acesso a informações previsto no inciso XXXIII do art. 5으, no inciso II do § 3 ㅇ do art. 37 e no $\S 2$ 을 do art. 216 da Constituição Federal; altera a Lei no 8.112, de 11 de dezembro de 1990; revoga a Lei no 11.111, de 5 de maio de 2005, e dispositivos da Lei no 8.159, de 8 de janeiro de 1991; e dá outras providências. Disponível em: http://www.planalto.gov.br/ccivil_03/_ato2011- 
Websites dos poderes executivos estaduais e as contratações emergenciais em meio à pandemia da COVID-19: há tecnologia, mas falta transparência

2014/2011/lei/l12527.htm. Acesso em: 22 maio 2020.

BRASIL. Lei $\mathbf{n}$. 13.979, de 06 de fevereiro de 2020. Dispõe sobre as medidas para enfrentamento da emergência de saúde pública de importância internacional decorrente do coronavírus responsável pelo surto de 2019. Disponível em:

http://www.planalto.gov.br/ccivil_03/_ato2019-2022/2020/lei/L13979.htm. Acesso em: 22 maio 2020.

CRESWELL, J. W. Projeto de pesquisa: métodos qualitativo, quantitativo e misto. Porto alegre: Artmed, 2007.

DREHMER, A. F.; RAUPP, F. M. Transparência passiva, formalismo e os poderes estaduais brasileiros. Revista Gestão \& Planejamento, Salvador, v. 20, n. 1, p. 273-291, jan./dez., 2019. DOI: 10.21714/2178-8030gep.v20.5855.

GIL, A. C. Métodos e técnicas de pesquisa social. São Paulo: Atlas, 1999.

GOMES FILHO, A. B. O desafio de implementar uma gestão pública transparente. In: Congreso Internacional del CLAD sobre la Reforma del Estado y de la Administración Pública, 10., 2005, Santiago. Anais eletrônicos [...]. Santigado, 2005. Disponível em: https://cladista.clad.org/bitstream/handle/123456789/3543/0052549.pdf?sequence=1\&isAl lowed=y. Acesso em: 03 nov. 2020.

JAHNS, F. T.; RAUPP, F. M. Transparência do poder executivo dos estados brasileiros. Revista Universo Contábil, Blumenau, v. 12, n. 3, p. 65-72, jul./set., 2016. DOI:10.4270/ruc.2016321.

LOUREIRO, M. R.; TEIXEIRA, M. A. C.; PRADO, O. Construção de instituições democráticas no Brasil contemporâneo: transparência das contas públicas. Organizações \& Sociedade, Salvador, v. 15, n. 47, art. 6, p. 107-119, out./dez., 2008. DOI: 10.1590/S198492302008000400006.

MACHADO-DA-SILVA, C. L.; GUARIDO FILHO, E. R.; NASCIMENTO, M. R.; OLIVEIRA, P. T. Institucionalização da mudança na sociedade brasileira: o papel do formalismo. In: VIEIRA, M. M. F.; CARVALHO, C. A. (Orgs.). Organizações, instituições e poder no Brasil. Rio de Janeiro: Editora FGV, 2003. p. 179-202.

OPEN KNOWLEDGE BRASIL (OKBR). Quase metade dos estados apresenta dados conflitantes sobre a Covid-19. 2020. Disponível em:

https://transparenciacovid19.ok.org.br/files/Transparencia-Covid19_Boletim_8.pdf. Acesso em: 26 maio 2020.

MOTTA, F. P.; ALCADIPANI, R. Jeitinho brasileiro, controle social e competição. Revista de Administração de Empresas, São Paulo, v. 39, n. 1, p. 6-12, jan./mar., 1999. DOI: 10.1590/S0034-75901999000100002.

PLATT NETO, O. A.; CRUZ, F.; ENSSLIN, S. R.; ENSSLIN, L. Publicidade e transparência das 
contas públicas: obrigatoriedade e abrangência desses princípios na administração pública brasileira. Contabilidade Vista \& Revista, Belo Horizonte, v. 18, n. 1, p. 75-94, jan./mar., 2007. Disponível em:

https://revistas.face.ufmg.br/index.php/contabilidadevistaerevista/article/view/320. Acesso em: 26 maio 2020.

RAMOS, A. G. Administração e contexto brasileiro: esboço de uma teoria geral da Administração. Rio de Janeiro: Editora FGV, 1983.

RIGGS, F. A ecologia da administração pública. Rio de Janeiro: Usaid, 1964.

RAUPP, F. M.; PINHO, J. A. G. de. Prestação de contas no legislativo local antes e depois da Lei de Acesso à Informação. Contexto, Porto Alegre, v. 15, n. 29, p. 30-46, jan./abr., 2015. Disponível em: http://repositorio.ufba.br/ri/handle/ri/21968. Acesso em: 26 maio 2020.

RAUPP, F. M.; PINHO, J. A. G. de. Review of passive transparency in Brazilian city councils. Revista de Administração, São Paulo, v. 51, n. 3, p. 288-298, jul./set. 2016. DOI: 10.1016/j.rausp.2016.02.001.

TRANSPARÊNCIA INTERNACIONAL BRASIL. Ranking de transparência no combate à Covid19: nota metodológica. 2020a. Disponível em:

https://comunidade.transparenciainternacional.org.br/asset/89:tibrnotametodologicarankingcovid?stream=1. Acesso em: 21 maio 2020.

TRANSPARÊNCIA INTERNACIONAL BRASIL. Ranking de transparência no combate a Covid19: base de dados. 2020b. Disponível em:

https://transparenciainternacional.org.br/ranking/. Acesso em: 21 maio 2020.

TRANSPARÊNCIA INTERNACIONAL BRASIL. Recomendações para transparência de contratações emergenciais em resposta à Covid-19. 2020c. Disponível em:

https://comunidade.transparenciainternacional.org.br/asset/86:tibr-recomendacoes-decontratacoes-emergenciais-covid19?stream=1. Acesso em: 22 maio 2020.

TRANSPARÊNCIA INTERNACIONAL BRASIL. O que é a transparência internacional? 2020d. Disponível em: https://transparenciainternacional.org.br/quem-somos/perguntasfrequentes/. Acesso em: 02 nov. 2020. 